\title{
SISTEM INFORMASI PROMOSI DAN PENDAFTARAN MAHASISWA BARU PROGRAM STUDI MANAJEMEN INFORMATIKA DI STMIK “AMIKBANDUNG"
}

\author{
Taofik Anugrah Putra ${ }^{1}$, Hermawaty ${ }^{2}$ \\ STMIK AMIKBANDUNG \\ Email: taofik.anugrah.tap@gmail.com ${ }^{1}$,emma@stmik-amikbandung.ac.id ${ }^{2}$
}

\begin{abstract}
ABSTRAK
STMIK “AMIKBANDUNG” adalah Sekolah Tinggi Manajemen Informatika Komputer di daerah Jalan Jakarta, Bandung yang setiap harinya melakukan proses kegitan akademik belajar mengajar untuk mendidik mahasiswa mahasiswi di bidang IT. Permasalahan yang di hadapi STMIK “AMIKBANDUNG” adalah sistem informasi pendaftaran mahasiswa baru jurusan Program Studi Manajemen Informatika masih menggunakan proses pencatatan dengan cara mengisi form kertas dan promosi jurusan Program Studi Manajemen Informatika pun masih menggunakan brosur. Kekurangan pada proses tersebut yaitu sering kali kehilangan histori pendaftaran, proses pendaftaran terkesan lama, laporan yang dirasa kurang detail, jangkauan promosi pun terbatas , dan masih sering terjadi kesalahan data.

Penelitian yang dilakukan yaitu membuat sistem baru yang dapat menyelesaikan masalah promosi dan pendaftaran mahasiswa baru di STMIK "AMIKBANDUNG" berbasis website. Dalam proses perancangannya, sistem ini menggunakan UML dan dibangun menggunakan bahasa pemrograman PHP. Penulis juga menggunakan phpMyAdmin untuk mengelola database di MySQL dan Sublime Text untuk menuliskan teks/kode program.

Dengan adanya sistem ini pada bagian pendaftaran dan registrasi Program Studi Manajemen Informatika STMIK “AMIKBANDUNG”, diharapkan dapat memperluas jangkauan promosi, mengurangi presentase kesalahan, dan kehilangan data, serta memperlancar proses pendaftaran mahasiswa baru Program Studi Manajemen Informatika STMIK “AMIKBANDUNG”.
\end{abstract}

Kata kunci: Promosi, Pendaftaran, STMIK “AMIKBANDUNG”, Program Studi, PHP, website, mahasiswa, Manajemen Informatika

\section{PENDAHULUAN}

\subsection{Latar Belakang}

Kemajuan teknologi dan informasi merupakan bagian penting untuk kehidupan manusia sekarang ini,website dan internet merupakan media penyampaian informasi atau sebagai media pelayanan yang efektif dan efisien, dengan jaringan internet kita dapat menjelajah tanpa batas ruangwaktu selama tersambung kejaringan internet. Kemajuan dunia internet sekarang ini sangat pesat dan telah menuntut banyak orang untuk memanfaatkan dunia maya dalam setiap aktivitasnya di dunia nyata. 
STMIK “AMIKBANDUNG” adalah Sekolah Tinggi Manajemen Informatika Komputer di daerah Jalan Jakarta, Bandung yang setiap harinya melakukan proses kegitan akademik belajar mengajar untuk mendidik mahasiswa mahasiswi di bidang IT. Salah satu jurusan yang ada di sekolah tinggi ini yaitu Manajemen Informatika. Program Studi Manajemen Informatika dalam mempromosikan jurusan masih dengan cara konvensional dan pendaftaran pun masih manual. Bagaimana merancang media promosi pendaftaran berbasis website yang sesuai untuk Program Studi Manajemen Informatika. Sehingga penulis tertarik untuk membuat website sesuai dengan permasalahan yang dihadapi oleh Program Studi Manajemen Informatika.

Disini akan dirancang dan dibuat sebuah website promosi dan pendaftaran Mahasiswa baru dimaksudkan untuk memudahkan pendaftaran. Agar calon Mahasiswa baru mudah mengetahui lebih dalam jurusan Program Studi Manajemen Informatika STMIK “AMIKBANDUNG”. Mempromosikan dan pendaftaran harus disertaidengan konsep yang mudah agar calon Mahasiswa baru mudah mengaksesnya. Maka dari itu penulis akan membuat sebuah websitedengan judul "Sistem Informasi Promosi dan Pendaftaran Mahasiswa Baru Prodi Manajemen Informatika di STMIK "AMIKBANDUNG".

\subsection{Identifikasi Masalah}

Berdasarkan latar belakang masalah, maka penulis dapat mengambil kesimpulan berupa pokok permasalahan yaitu sebagai berikut :

1. Informasi mengenai jurusan Program Studi Manajemen Informatika STMIK “AMIKBANDUNG" masih dengan cara konvensional.

2. Sistem pendaftaran Mahasiswa baru Program Studi Manajemen Informatika STMIK “AMIKBANDUNG” masih manual belum terkomputerisasi.

\subsection{Rumusan Masalah}

Berdasarkan identifikasi masalah, penulis dapat merumuskan masalah di antaranya yaitu:

1. Bagaimana membangun aplikasi yang dapat memberikaninformasi tentang visi dan misi jurusan Program Studi Manajemen Informatika STMIK “AMIKBANDUNG”? 
2. Bagaimana membuat sistem informasi promosi dan pendaftaran berbasis website agar calon Mahasiswa baru tidak perlu mendatangi kampus untuk mendaftar ke Program Studi Manajemen Informatika STMIK “AMIKBANDUNG”?

\subsection{Tujuan}

Adapun tujuan yang ingin dicapai sebagai berikut :

1. Memudahkan bagian pendaftaran Program Studi Manajemen Informatika STMIK "AMIKBANDUNG".

2. Memudahkan calonMahasiswa baru dalam mendaftar ke Program Studi Manajemen Informatika STMIK “AMIKBANDUNG” melalui sistem berbasis website.

3. Dapat memperluas jangkauan promosi, mengurangi presentase kesalahan, dan kehilangan data, serta memperlancar proses pendaftaran mahasiswa baru Program Studi Manajemen Informatika STMIK “AMIKBANDUNG”.

\subsection{Batasan Masalah}

Agar penyelesaian masalah yang dilakukan tidak menyimpang dari ruang lingkup pembahasan, maka akan dilakukan pembatasan masalah. Adapun batasan masalah ini, yaitu sebagai berikut :

1. Menggunakan bahasa pemrograman PHP dan database MySql.

2. Website menampilkan form input pendaftaran untuk calon mahasiswa baru.

3. Memberikaninformasi tentang visi dan misi jurusan Program Studi Manajemen Informatika STMIK “AMIKBANDUNG”.

\subsection{Teknik Pengumpulan Data}

Pemilihan metode pengumpulan data dilakukan untuk memperoleh data yang lengkap, nyata, terbaru, serta sesuai dengan fakta di lapangan. Adapun metode yang akan digunakan adalah sebagai berikut :

1. Observasi

Pengamatan langsung ke lapangan dianggap penting agar dapat mengetahui situasi nyata tentang segala kegiatan yang sedang berjalan.

2. Studi Literatur 
Studi literatur dilakukan untuk mengetahui informasi berdasarkan catatan-catatan yang sudah dibuat sebelumnya serta memperoleh pengetahuan dalam penyelesaian yang ditemui.

\section{LANDASAN TEORI}

\subsection{Pengertian Sistem Informasi}

Menurut Bodnar dan Hopwood (2006:3), sistem merupakan sekumpulan sumber daya yang saling terkait yang ingin mencapai suatu tujuan. Menurut Hall (2009:6), sistem adalah sekelompok dari dua atau lebih subsistem yang mempunyaii hubungan dan memiliki suatu tujuan yang sama. Sedangkan informasi menurut Bodnar dan Hopwood (2006:3), menyatakan informasi merupakan suatu data yang diorganisasi yang dapat mendukung ketepatan pengambilan keputusan. Menurut Mulyadi (2001:43), informasi adalah olahan data ke dalam bentuk yang dapat memberikan arti bagi penerima dan dapat dijadikan sebagai dasar pengambilan keputusan saat ini atau mendatang. Dari uraian tersebut dapat disimpulkan sistem informasi menyiratkan penggunaan teknologi dengan komputer dalam organisasi atau perusahaan yang dapat menyediakan informasi bagi pihak-pihak yang membutuhkan dan pengguna.

\subsection{Pengertian Promosi}

Sebaik apapun mutu sebuah produk atau jasa, semenarik apapun bentuk rupanya atau sebesar apapun manfaatnya, jika tidak ada orang yang mengetahui tentang keberadaannya, maka mustahil produk atau jasa tersebut dibeli. Produk atau jasa yang sudah bagus dengan harga yang sudah bagus itu tidak dapat dikenal oleh konsumen maka produk atau jasa tersebut tidak akan berhasil di pasar. Sarana dan prasarana yang dibutuhkan secara efektif agar informasi mengenai hadirnya sebuah produk atau jasa, dapat sampai kepada masyarakat atau konsumen. Upaya untuk mengenalkan produk atau jasa itu kepada konsumen merupakan awal dari kegiatan promosi.

\subsection{Pengertian Pendaftaran}

Pengertian pendaftaran disini pada dasarnya hanya untuk memperlancar dan mempermudah dalam proses pendaftaran calon siswa baru, pendataan dan pembagian kelas seorang calon siswa baru. Sehingga dapat terorganisir, teratur dengan cepat dan 
tepat dengan beberapa persyaratan yang telah ditentukan oleh lembaga. Proses pendaftaran calon siswa baru merupakan salah satu kewajiban pihak lembaga dan Dinas Pendidikan setiap tahun ajaran baru[3].

\subsection{Pengertian Basis Data}

Basis data merupakan kumpulan data dari berbagai sumber yang secara logika mempunyai arti implisit. Sehingga data yang terkumpul secara acak dan tanpa mempunyai arti, tidak dapat disebut basis data.Basis data perlu dirancang, dibangun dan data dikumpulkan untuk suatu tujuan. Basis data dapat digunakan oleh beberapa user dan beberapa aplikasi yang sesuai dengan kepentingan user. Kumpulan informasi bermanfaat yang diorganisasikan ke dalam aturan yang khusus. Informasi ini adalah data yang telah diorganisasikan ke dalam bentuk yang sesuai dengan kebutuhan seseorang.

\subsection{Pengertian PHP}

PHP sendiri sebenarnya merupakan singkatan dari "Hypertext Preprocessor", yang merupakan sebuah bahasa scripting tingkat tinggi yang dipasang pada dokumen HTML. Sebagian besar sintaks dalam PHP mirip dengan bahasa C, Java dan Perl, namun pada PHP ada beberapa fungsi yang lebih spesifik. Sedangkan tujuan utama dari penggunaan bahasa ini adalah untuk memungkinkan perancang web yang dinamis dan dapat bekerja secara otomatis.

\subsection{Pengertian Website}

Website merupakan sebuah kumpulan halaman-halaman web beserta file-file pendukungnya, seperti file gambar, video, dan file digital lainnya yang disimpan pada sebuah web server yang umumnya dapat diakses melalui internet. Atau dengan kata lain, website adalah sekumpulan folder dan file yang mengandung banyak perintah dan fungsi fungsi tertentu, seperti fungsi tampilan, fungsi menangani penyimpanan data, dan sebagainya. 


\section{ANALISIS DAN PERANCANGAN}

\subsection{Deskripsi Sistem}

Sistem informasi promosi dan pendaftaran mahasiswa baruProgram Studi Manajemen Informatika STMIK “AMIKBANDUNG” merupakan sebuah sistem berbasis website. Sistem yang dibuat merupakan sistem baru yang menyelesaikan masalah promosi dan pendaftaran mahasiswa baru di STMIK "AMIKBANDUNG". Didalam sistem informasi ini juga disertakan Visi, Misi, dan Tujuan Program Studi Manajemen Informatika agar para mahasiswa baru lebih bisa memahami dan mendalami dari jurusan tersebut.

\subsection{Diagram Use Case}

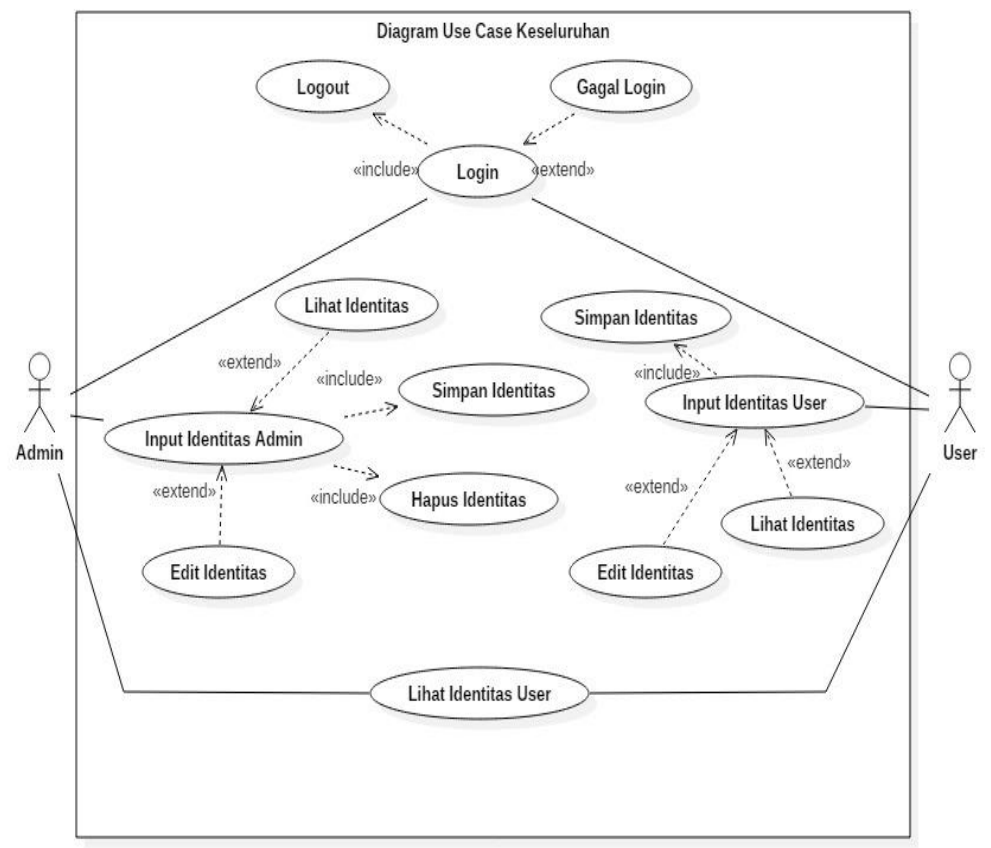

GAMBAR 3.1. Diagram Use Case Keseluruhan 


\subsection{Class Analisis}

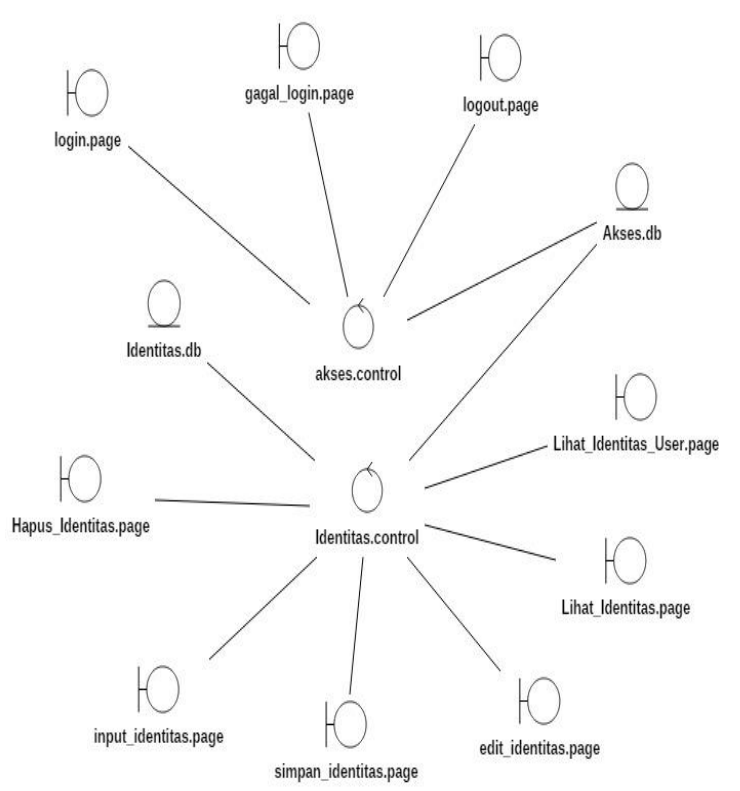

GAMBAR 3.2. Class Analisis Keseluruhan

\subsection{Activity Diagram}

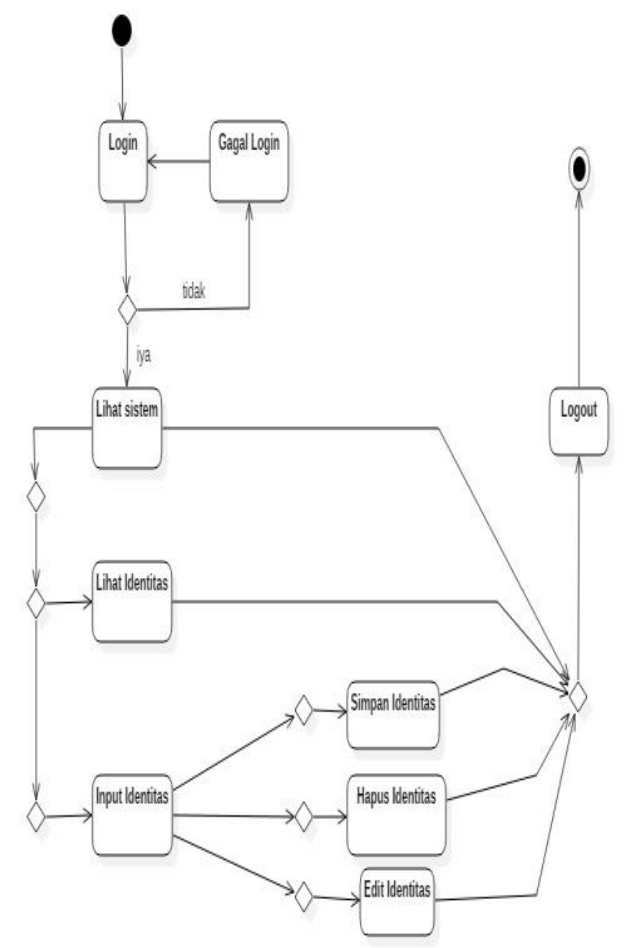

GAMBAR 3.3. Activity Diagram Admin 


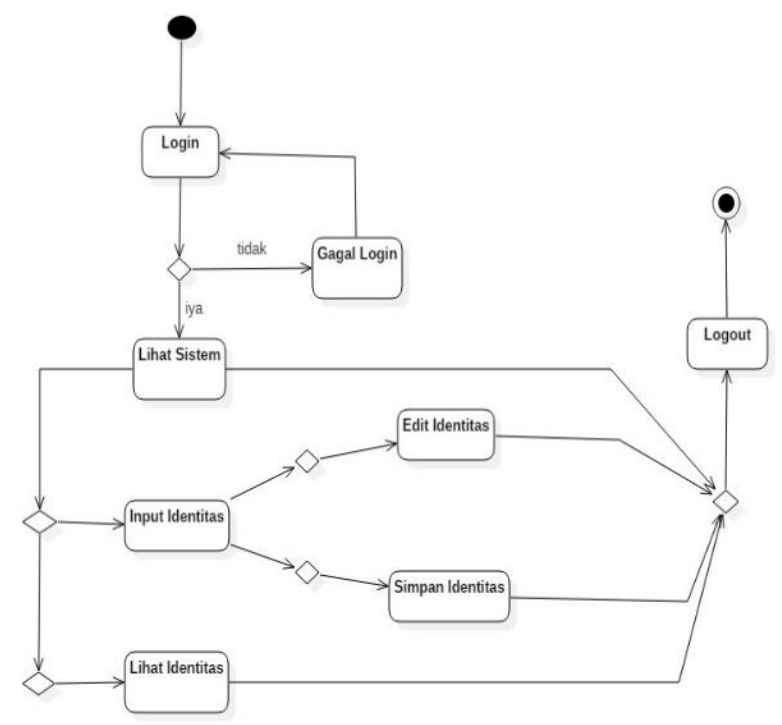

GAMBAR 3.4. Activity Diagram User

\subsection{Perancangan Antar Muka}

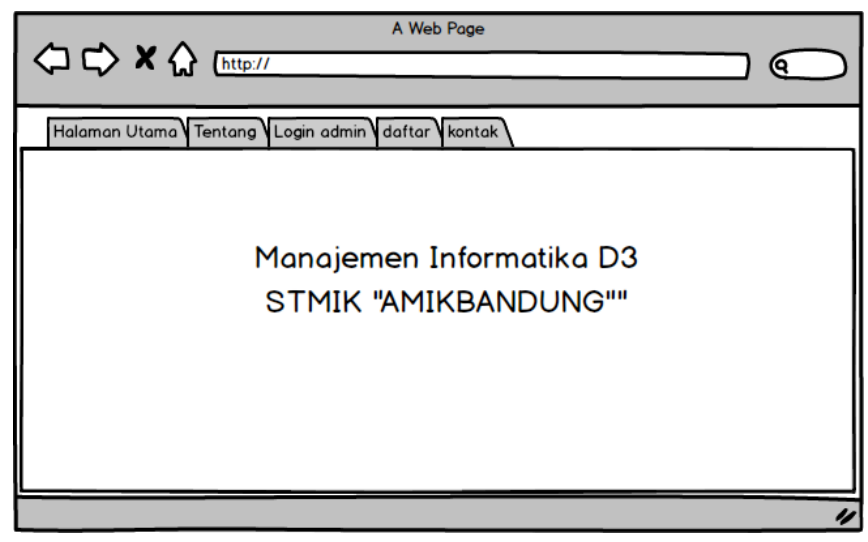

GAMBAR 3.5. Rancangan Antar Muka Halaman Utama

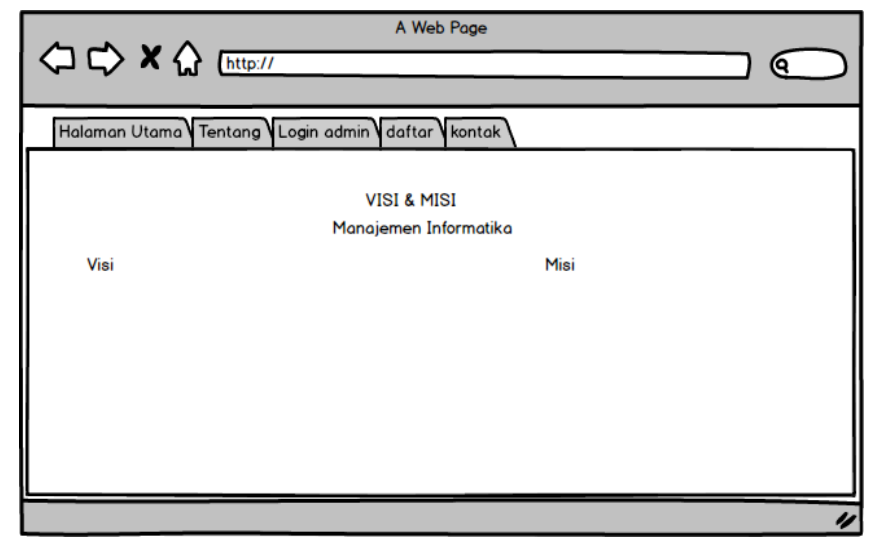

GAMBAR 3.6. Rancangan Antar Muka Visi dan Misi 


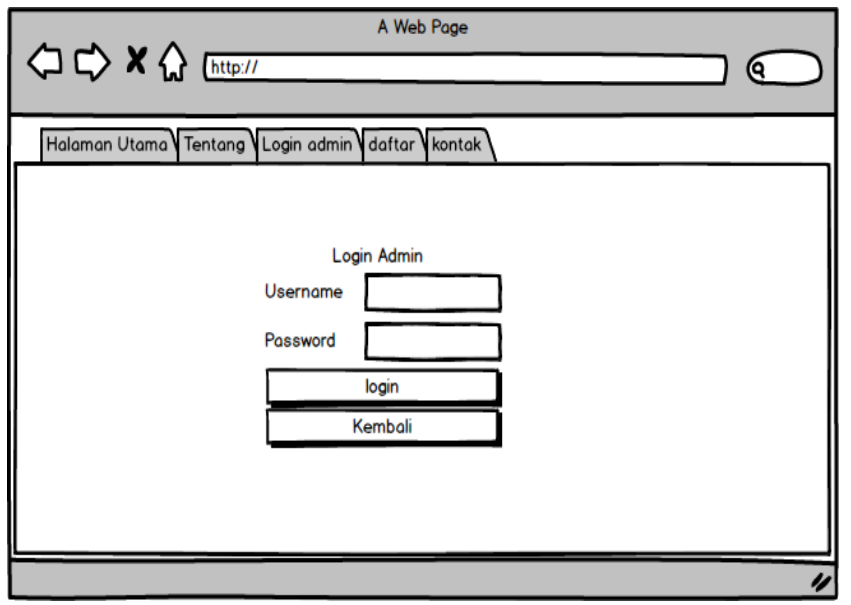

GAMBAR 3.7. Rancangan Antar Muka Login Admin

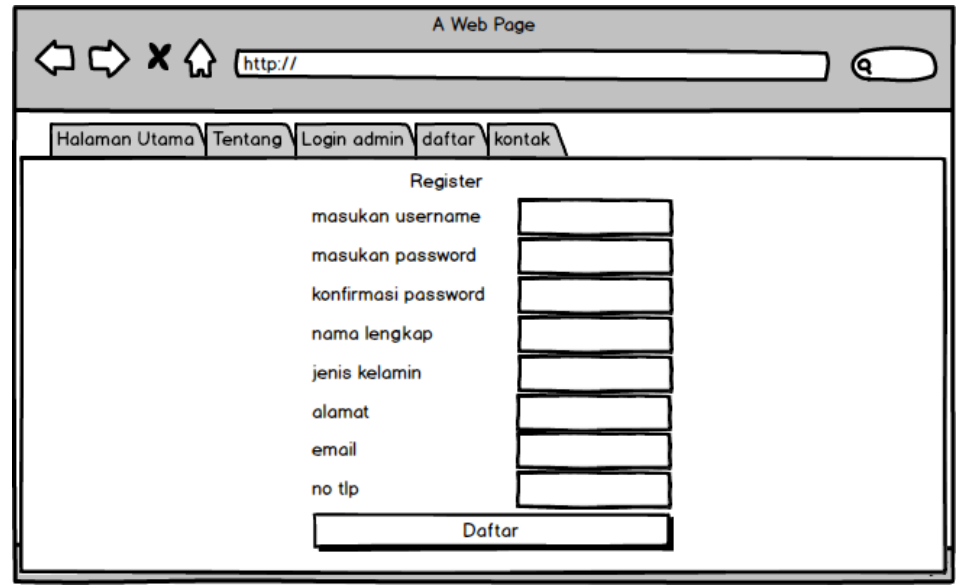

GAMBAR 3.8. Rancangan Antar Muka Login Admin

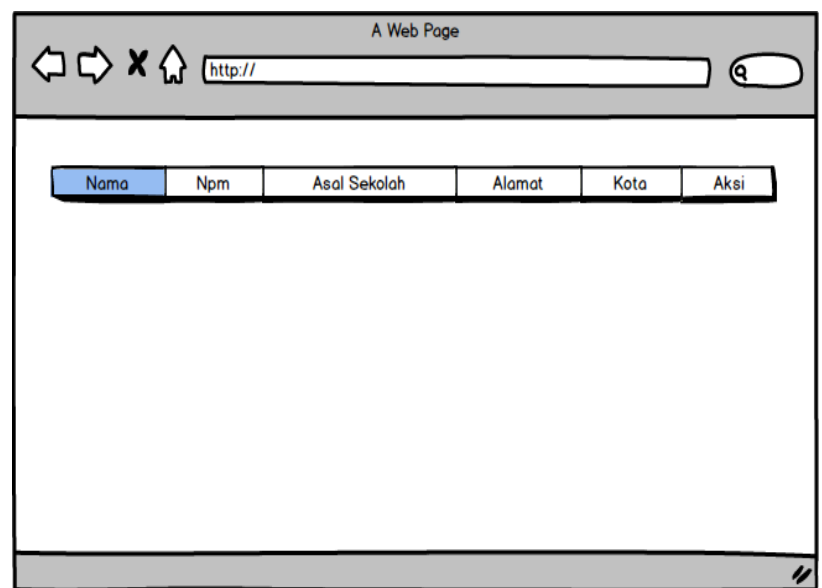

GAMBAR 3.9. Rancangan Antar Muka Admin Edit Data 


\section{IMPLEMENTASI}
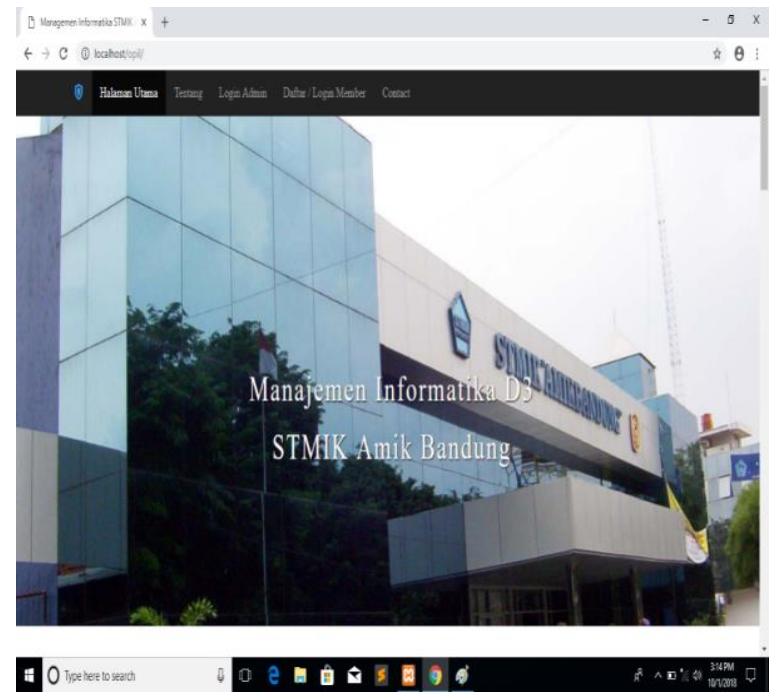

GAMBAR 4. 1. Antar Muka Halaman Utama
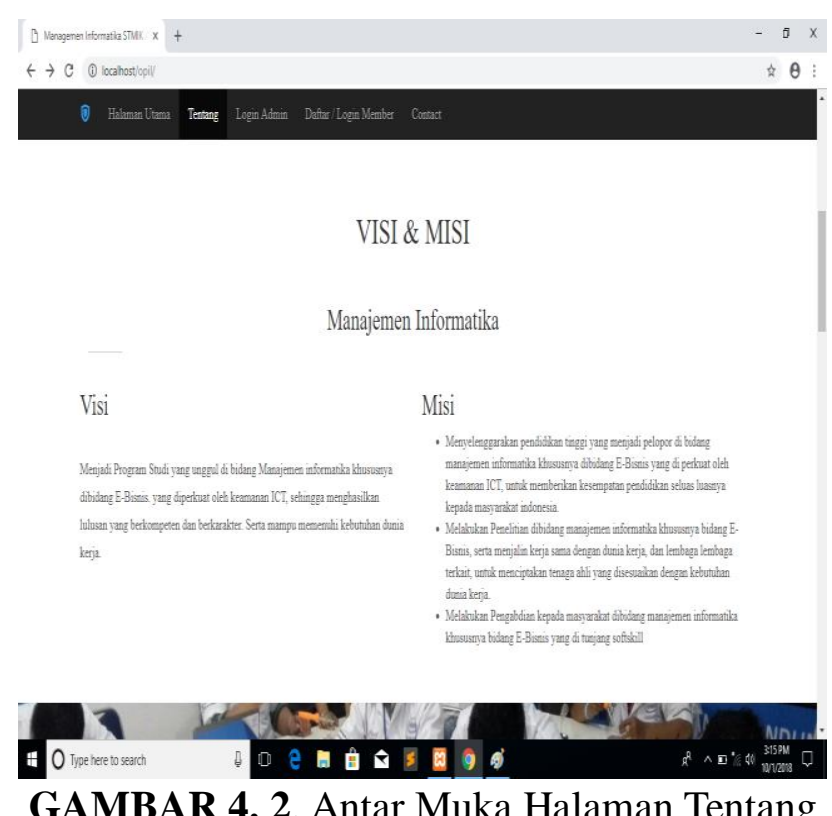


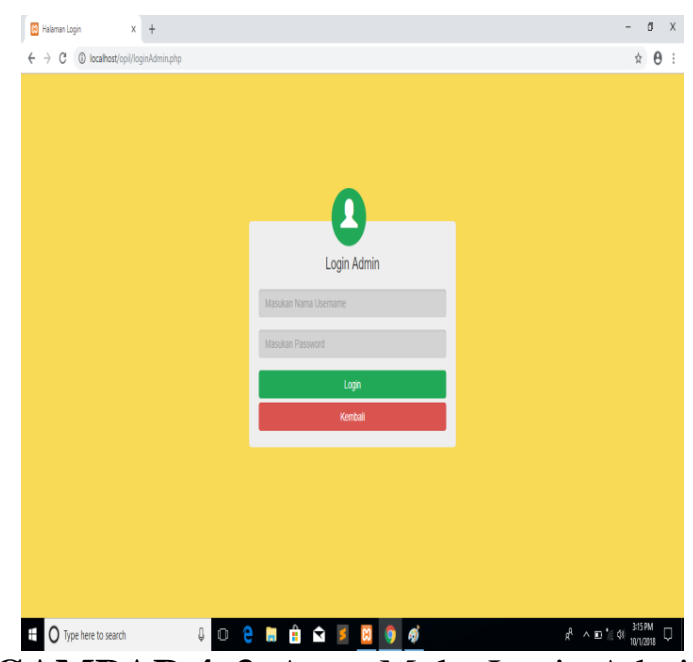

GAMBAR 4. 3. Antar Muka Login Admin

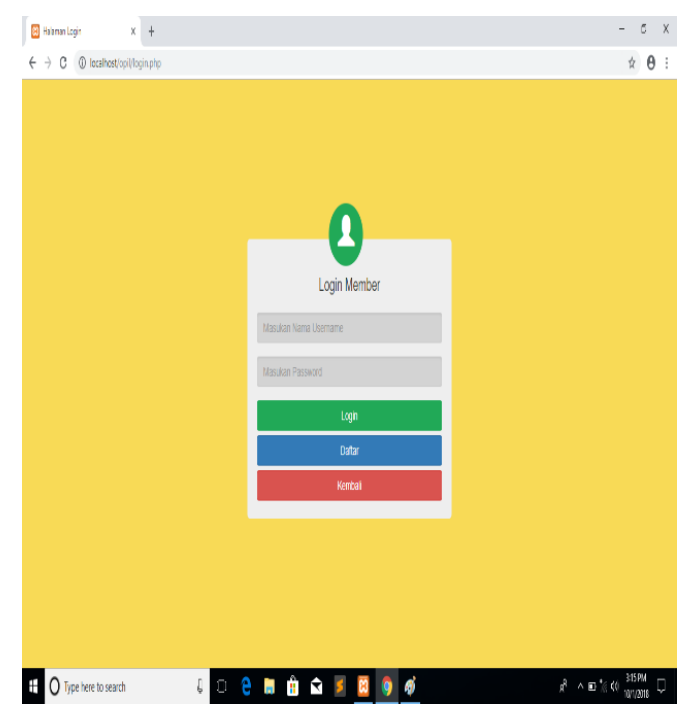

GAMBAR 4. 4. Antar Muka Login Member

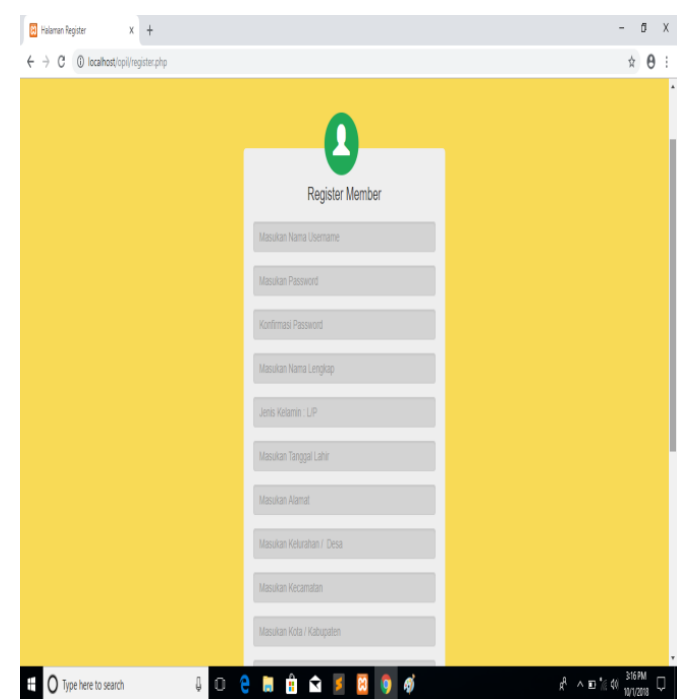

GAMBAR 4. 5. Antar Muka Pendaftar Mahasiswa Baru 


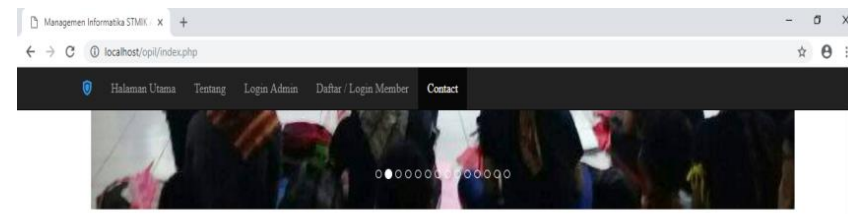

Kremat

Contact Information

คิ $\mu$ Jakarata No.28

$(+2821321893$

anifo-

STMIR AMIIBBANDUNG 1993

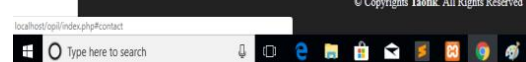

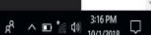

GAMBAR 4. 6. Antar Muka Kontak Manajemen Informatika
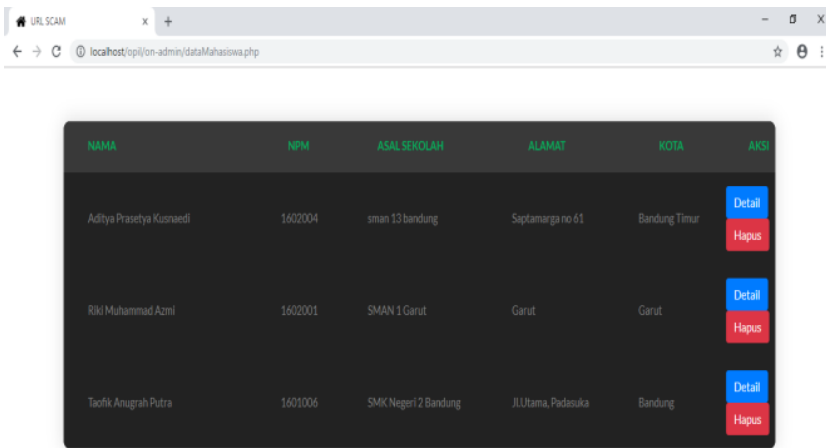

Kanbali

go

GAMBAR 4. 7. Antar Muka Identitas Mahasiswa Baru

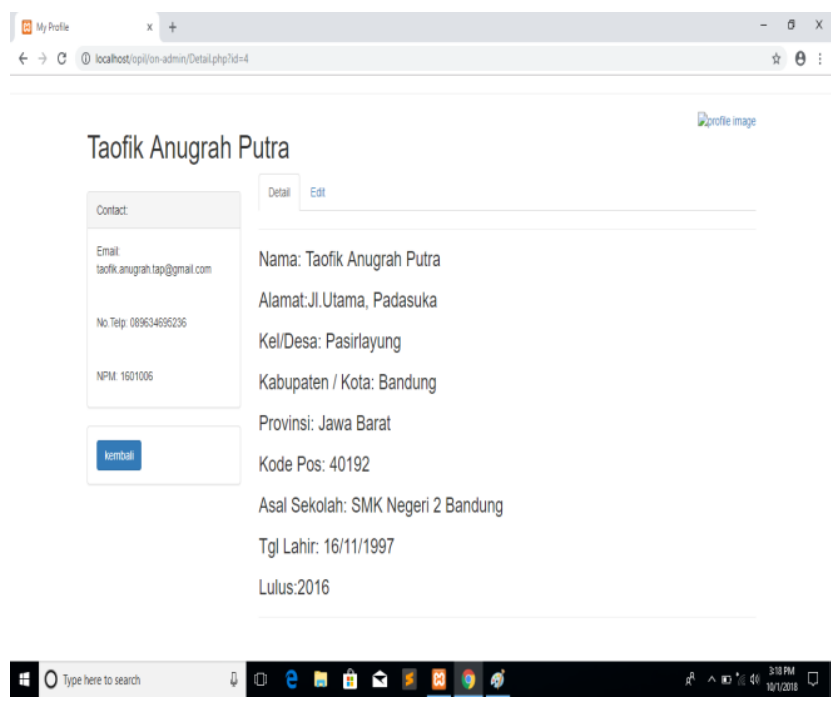

GAMBAR 4. 8. Antar Muka Halaman Profile 


\section{KESIMPULAN DAN SARAN}

\subsection{KESIMPULAN}

Kesimpulan dari pembuatan sistem informasi ini yaitu :

1. Setiappara pendaftaryang sudah ditambahkan ke dalam sistem secara otomatis akan tercatat di menu data identitas mahasiswa baru.

2. Sistem ini mendukung untuk memudahkan bagian pendaftaran Program Studi Manajemen Informatika STMIK “AMIKBANDUNG”dapat memperluas jangkauan promosi, mengurangi presentase kesalahan, dan kehilangan data, serta memperlancar proses pendaftaran mahasiswa baru Program Studi Manajemen Informatika STMIK “AMIKBANDUNG”.

\subsection{SARAN-SARAN}

Adapun saran yang ingin penulis sampaikan yaitu, sistem ini masih memiliki kekurangan dan keterbatasan, baik dari segi tampilan maupun fungsinya, sehingga akan lebih baik apabila sistem yang telah dibangun ini dikembangkan lagi agar dapat bekerja secara optimal.

\section{DAFTAR PUSTAKA}

A. USMAN, "Sistem Informasi," dalam Pengantar Sistem Informasi, Pekanbaru, Creative Team, 2011, pp. 2-3.

I. Basu Swastha, Manajemen Pemasaran Modern, Yogyakarta: Liberty, 2003.

F. Mussi, Arti Kata Register, Bandung: UNIKOM, 2015.

H. Dzacko, "Data Informasi Basis Data," dalam BASIS DATA (DATABASE), Jakarta, Mangosoft, 2007, pp. 17-19.

A. L. K. Ratna, "PENGERTIAN PHP DAN MYSQL," dalam Ilmu Teknologi Informasi, Jakarta, iLmuti, 2014, pp. 5-6.

H. Hartono, "WEBSITE DAN FUNGSINYA," dalam Ilmu Teknologi Informasi, Jakarta, iLmuti, 2014, p. 2. 